\title{
“A POETICAL DIMENSION": RETÓRICA E POESIA EM THE ARCADIAN RHETORIKE (1588), DE ABRAHAM FRAUNCE
}

\author{
LAVINIA SiLVARES \\ Universidade Federal de São Paulo (UNIFESP)
}

\begin{abstract}
Resumo. Dentre as artes retóricas compostas na segunda metade do século XVI na Inglaterra, The Arcadian Rhetorike (1588), de Abraham Fraunce (c.1559-c.1593), apresenta uma diferença marcante. Se as artes retóricas do período propunham via de regra a partição antiga da retórica em cinco partes, o tratado de Fraunce divide-a em apenas duas partes: Elocução e Pronunciação. Seguindo de perto a proposta de Pierre de la Ramée (ou Petrus Ramus), Fraunce introduz na Inglaterra a divisão pela qual caberão somente à Lógica as partes da invenção e da disposição, e somente à Retórica as partes da elocução e da ação. Exemplificando tropos, figuras, voz e gestos com poemas em grego, latim, inglês, italiano, francês e espanhol - de Homero, Virgílio, Sidney, Spenser, Petrarca, Tasso, Du Bartas, Boscán e Garcilaso, entre outros - Fraunce expõe os mecanismos retóricos da formulação da poesia, tal qual se concebia em seu tempo. Neste artigo, proponho-me a (1) apresentar as características principais da retórica "arcádia" de Fraunce, analisando as circunstâncias históricas de sua composição; (2) examinar a relação que mantém com outras artes retóricas e poéticas; e (3) discutir a importância que teve para a escrita de poesia no âmbito letrado da corte inglesa.
\end{abstract}

Palavras-chave. Retórica, poesia, século XVI, The Arcadian Rhetorike, Abraham Fraunce.

Ao LONGo do SÉculo XVI, HOUVE NA CORTE DA RAINHA Elisabeth UM grande incentivo ao regramento do vernáculo e a seu uso como língua padrão para a escrita de tratados de gramática, retórica e lógica, antes compostos em latim. Como seus colegas das cortes continentais, os ingleses definiam também nesse período novas regras gramaticais - de etimologia, ortografia, sintaxe - e preceitos de composição no vernáculo, defendendo a copiosidade da língua inglesa e sua aptidão para os fins elevados e cultos dos âmbitos letrados emergentes. Ao mesmo tempo em que se dava o processo de fortalecimento político e bélico da corte, era crescente a produção em inglês de textos prescritivos e poéticos que formavam e reformavam o domínio culto dos saberes para um público cortesão igualmente culto, instruído nas artes canônicas e liberais. Em carta ao poeta Edmund Spenser, 
Harvey (1580), então preletor de retórica em Cambridge, julgava fundamental o regramento da língua inglesa a partir de leis mais estáveis de ortografia e de composição para que se tornasse de fato apta ao domínio das artes:

I am of Opinion, there is no one more regular and justifiable direction, eyther for the assured, and infallible Certaintie of our English Artificiall Prosodye particularly, or generally to bring our Language into Arte, and to frame a Grammer or Rhetorike thereof: than first of all uniuersally to agree upon one and the same Ortographie, in all pointes conformable and proportionate to our Common Natural Prosodye [...].

Assim, seguindo modelos continentais de defesa das línguas vernaculares - como Prose della volgar lengua (1525), de Pietro Bembo; La defence et illustration dela langue françoyse (1549), de Joachim du Bellay; Osservatione nella volgar lengua, de Lodovico Dolce (1550), entre várias outras obras do gênero -, também os ingleses advogavam a composição em vernáculo de tratados das diversas artes, de manuais técnicos de composição nos variados gêneros e a tradução de obras antigas importantes para o inglês, cada vez mais comuns no reino. Nessas novas obras, circulavam lugares discursivos formativos de um passado histórico da língua e das letras, cristalizando, por assim dizer, as tópicas de grandeza do reino inglês que seriam repetidamente usadas ao longo dos séculos xvi e xvir. Se os personagens figurados nessas tópicas apareciam como "novidade" - os vernáculos recentemente refinados, os novos padrões métricos e as rimas da poesia, as contingências diplomáticas que surgem das guerras religiosas pós-Reforma, a crescente centralização do poder monárquico, etc. -, por outro lado os mecanismos dialético-retóricos pelos quais esses discursos se edificam são muito antigos.

É nessa contingência de imitação e de emulação de preceitos poéticos e retóricos antigos e contemporâneos que surge a "retórica arcádia" de Abraham Fraunce. Mestre pelo St. John's College da Universidade de Cambridge, casuístico do Grey's Inn e poeta vinculado ao círculo letrado da corte inglesa, Fraunce teve uma carreira comum a poetas e retores do âmbito letrado inglês: de origem não nobre, foi patrocinado pelo círculo de Sir Philip Sidney e, depois, de sua irmã, a condessa de Pembroke (a quem Fraunce dedica sua retórica arcádia), recebendo favorecimentos e incentivos para a publicação de seus poemas e tratados. Desde o período em que estudou no St. John's College, em Cambridge, conviveu com os chamados "university wits" (os "engenhosos da universidade"), como os poetas Robert Greene, Thomas Nashe, John Webbe e Christopher Marlowe. Depois, atuando em direito canônico no Grey's Inn, conviveu com poetas e grandes nomes do âmbito letrado inglês como Sir Fulke Greville e Thomas Campion. Além da arte retórica e da arte dialética aqui mencionadas, Fraunce publicou também um livro de empresas, intitulado Abrahami Fransi Insig- 
nium Armorum (1588); uma versão do poema Aminta, de Tasso, publicada sob o título de The Countesse of Pembroke's Yoychurch (1591); uma tradução da segunda écloga de Virgílio, publicada sob o título de The Lamentation of Corydon for the love of Alexis (1592). Além de publicar essas obras, sabe-se que Fraunce participou da cena teatral inglesa, compondo pequenas peças e às vezes atuando em outras. Teve papel fundamental na publicação de obras poéticas de Spenser e Sidney, de quem era muito próximo. Apesar de tantas produções importantes, pouco se escreveu sobre as obras de Abraham Fraunce na crítica literária de língua inglesa; mesmo sua arte retórica só foi publicada, no século xx, em raríssimas edições de poucos exemplares. ${ }^{1}$

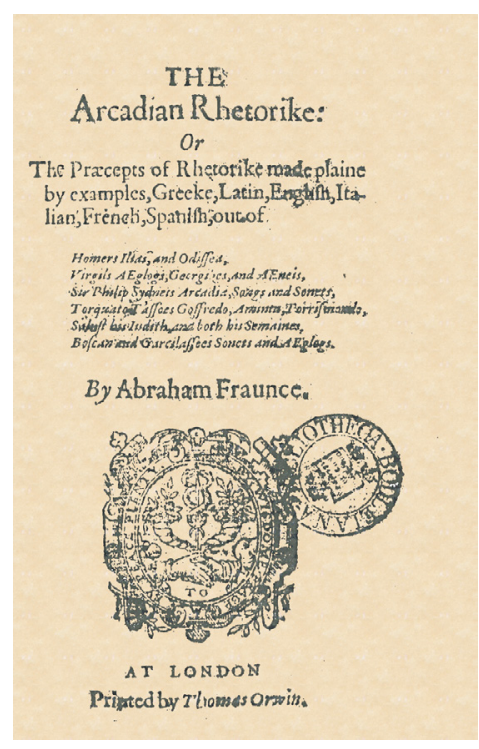

Figura 1. The Arcadian Rhetorike (1588), folha de rosto.

Publicada pois em Londres, em 1588, no mesmo ano da vitória inglesa sobre a até então "invencível armada" espanhola no canal da Mancha, The Arcadian Rhetorike [Figs. 1 e 2] apresenta algumas diferenças fundamentais em relação às demais artes retóricas compostas na Inglaterra no mesmo período ou em décadas anteriores. ${ }^{2}$ Em vez de propor a divisão antiga da retórica em cinco partes - invenção, elocução, disposição, memória e ação -, dada, por exemplo, na tão acatada Retórica a Herênio, Fraunce segue o modelo estabelecido pelo professor de retórica da Universidade de Paris, Pierre de la Ramée, mais conhecido na Inglaterra pela versão latina de seu nome, Petrus Ramus. O modelo ramista permite que Fraunce se concentre no domínio da elocução, expondo e comentando o uso de tropos e figuras em relação à efetuação das paixões e dos afetos. Ademais, a obra de Fraunce também se distingue ao eleger a arte poética, e não a oratória, como referência e fonte de exemplificação. Isto é, da expressão metafórica dos versos poéticos, Fraunce extrai os exemplos que comporão a sua retórica arcádia. Para examinar como se dá essa preceituação retórico-poética, proponho-me a (1) apresentar as características principais da arte retórica de Fraunce, analisando as circunstâncias históricas de sua composição; (2) examinar a rela-

\footnotetext{
Para uma breve apresentação da participação de Fraunce no âmbito letrado inglês, cf. May 2011.

2 A respeito das artes retóricas e poéticas publicadas na Inglaterra ao longo do século XVI e da emulação que faziam de preceitos antigos e coetâneos, cf. Silvares 2009.
} 


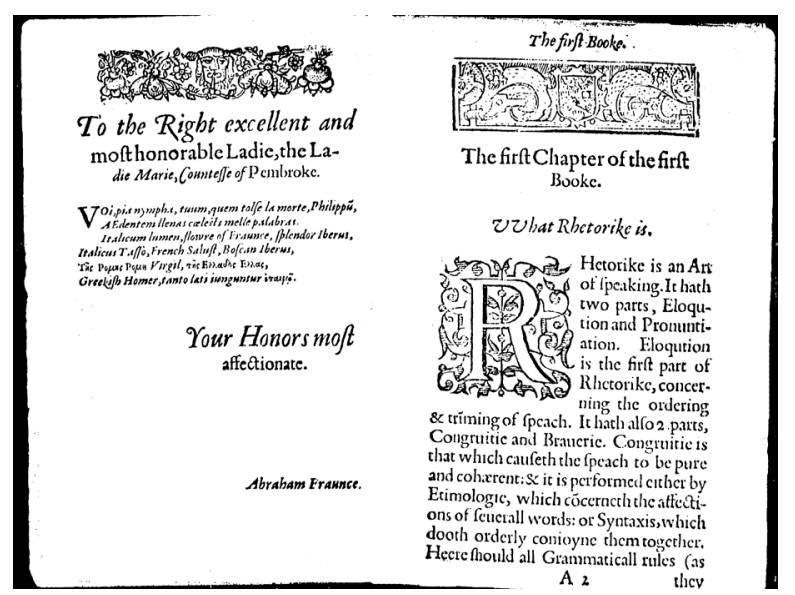

Figura 2.

The Arcadian Rhetorike (1588), p. 1 e 2.

ção que mantém com outras artes retóricas e poéticas; e (3) discutir a importância que teve para a escrita de poesia no âmbito letrado da corte inglesa.

Também em 1588, foi publicada em Londres a arte dialética de Fraunce, intitulada The Lawiers Logike, consistindo, segundo os dizeres do prólogo, em "uma explanação facilitada da lógica de Ramus" para uso dos casuísticos dos Inns of Court. A publicação desses dois tratados - de retórica e de lógica - introduz, na Inglaterra, o modelo ramista de reordenação das partes atribuídas às duas artes, o que implica uma reformulação de suas funções e a ênfase na copiosa exemplificação tanto dos argumentos lógicos quanto dos ornamentos retóricos com passos de autoridades nos variados gêneros.

Seguindo também a advertência feita por Ramus em sua Lógica, Fraunce enfatiza que um tratado não pode desvincular-se do outro, já que na prática - embora não mais na teorização delas - as duas artes se unem. ${ }^{3}$ A publicação no mesmo ano de The Arcadian Rhetorike e de The Lawiers Logike aponta para a complementaridade das artes no sistema proposto. ${ }^{4}$ No entanto, a arte dialética de Fraunce já havia circulado em Londres sete anos

\footnotetext{
3 "The apocopated Ramist rhetoric was always to be used with Ramist dialectic, which supplied all excised parts" (Ong 2004, 285).

${ }^{4}$ Cf. Howell 1956, 257, em que o autor argumenta que a ausência de indicação explícita ao modelo ramista na arte retórica de Fraunce instalou, na crítica, a compreensão equivocada de que se tratava de uma redução pragmatista da retórica: "Fraunce obviously intended it and his Lawiers Logike to serve together as the means of introducing his countrymen to Ramus' complete theory of communication. But by publishing his two works separately, and by giving no open indication that his Rhetorike has its origins in Ramism, he inadvertently fostered the early twentieth-century belief that the latter treatise was in one sense a continuation of the stylistic pattern of traditional rhetorical theory and in another sense, a seemingly capricious renunciation of invention and disposition as concerns of the man of eloquence."
} 
antes, sob o nome de The Shepheardes Logike, dedicada a Sir Philip Sidney. Nessa versão inicial, os exemplos de argumentos são tirados principalmente das éclogas pastoris de The Shepheardes Kalender (1579), de Edmund Spenser. No prefácio à edição expandida de 1588, Fraunce diz que a versão anterior de sua Lógica apresentava uma comparação das formulações sobre dialética feitas por Ramus e Aristóteles, e que decidiu manter, na mais recente versão, os exemplos dos versos de Spenser que constavam anteriormente:

I first began, (when I first came into presence of that right noble and most renowned knight sir Philip Sydney) with a generall discourse concerning the right vse of Logike, and a contracted comparison betweene this of Ramus and that of Aristotle. [...]I haue retayned those ould examples of the new Shepheards Kalender, which I first gathered, and therevnto added these also out of our Law bookes, which I lately collected.

Tanto no caso da retórica quanto no caso da lógica de Fraunce, portanto, a poesia figurava como exemplo primeiro, evidenciando que o entendimento da prática poética que se dá nessas obras engloba tanto a invenção de argumentos pela dialética quanto a ornamentação da linguagem pela retórica. Exemplificando o argumento de causa, Fraunce dá uns versos de The Shepheardes Kalender em que Hobbinol, personagem-cantor das éclogas do calendário spenseriano, declara que a desleal Rosalind é a causa de seu lamento:

So in the end of the first Aegloge of the Shepheardes Kalender, Hobbinol useth an argument of the cause, onely for explication sake.

Ah faithlesse Rosalynde, and voide of grace,

Thou art the roote of all this ruthfull woe.

E também quando trata da causa eficiente, Fraunce lança mão de um exemplo extraído de versos de Spenser em que se formulam causas eficientes particulares de deleite e prazer:

In June Hobbinoll reciteth a number of particular efficients of delight and pleasure, describing thereby the place where he was, thus:

Loe Collyn here the place whose pleasant sight

From other shades hath weand my wandring minde,

Tell me what wants me here to worke delight?

The simple ayre, the gentle warbling winde,

So calme, so coole, as no where els I finde.

The grassy ground with dainty daysies dight,

The bramble bush, where birds of euery kinde

To the waters fall their tunes attempter right. 
O fato de elencar versos da poesia bucólica de Spenser, então recém-publicada em Londres, e da Arcadia de Sidney - ainda não publicada em edição impressa - mostra a ativa participação de Fraunce no processo de legitimação da produção poética inglesa, alçando-a a um patamar análogo ao das autoridades antigas, das quais eram tradicionalmente retirados trechos para exemplificação nos tratados sobre as artes. Cabe examinar brevemente, a seguir, o modelo ramista a partir do qual Fraunce desenvolve seu entendimento de uma lógica tópica e de uma retórica elocutiva.

\section{O MODELO RAMISTA: UMA ÚNICA TEORIA DA INVENÇÃO}

Em 1543, Ramus publicou em Paris seu tratado Dialecticae Institutiones - depois traduzido para o inglês sob o título de The Logike of the Moste Excellent Philosopher P. Ramus Martyr, e publicado em Londres em $1574 .{ }^{5}$ Tomando como base a produção contemporânea de tratados acadêmicos sobre dialética e retórica e o modelo de ensino das artes nos currículos escolares, Ramus apontou um suposto equívoco em relação à delimitação das propriedades atribuídas a cada arte, condenando, sobretudo, repetições, imprecisões e definições sobrepostas das partes cabíveis a cada uma. Seu projeto de revisão das leituras escolásticas e humanistas da doutrina aristotélica e dos preceitos ciceronianos é complexo e exigiria uma discussão mais longa e aprofundada do que a que se propõe fazer aqui. Muito resumidamente, $\mathrm{o}$ que interessa ressaltar na revisão empreendida por Ramus é a proposição de um método único que compreende que uma única arte, a lógica, trataria da invenção e da disposição dos argumentos tanto para o uso da ciência (scientia) como para o uso da opinião: "Dialecticke otherwise called Logicke, is an arte which teachethe to dispute well. It is diuyded into two partes: Inuention, and iudgement or Disposition" (Ramus 1574, 17). Nessa perspectiva, a invenção é parte primeira da dialética e somente da dialética, servindo para as finalidades tanto de juízo de proposições quanto de argumentos de opinião, seja no âmbito forense, seja no âmbito letrado em geral. Essa proposta confronta, principalmente, o modelo aristotélico-escolástico então vigente que tratava da invenção e da disposição diferentemente para o uso de dialéticos

\footnotetext{
${ }_{5}^{5}$ Ramus era considerado "mártir" na Inglaterra protestante por ter morrido durante o massacre de São Bartolomeu, em Paris, em 1572. A morte de protestantes "ilustres" como Ramus e o compositor Claude Goudimel em Paris teve grande repercussão na corte inglesa, figurando inclusive como matéria poética (cf. Oliver 1968). Buxton 1966, 84 mostra o impacto do massacre no círculo letrado dos Sidney.
} 
e de rétores ou oradores, e que tratava da ornamentação do discurso tanto na gramática quanto na retórica:

But because of these two species, Aristotle wanted to make two logics, one for science, and the other for opinion; in which (saving the honor of so great a master) he has very greatly erred. For although articles of knowledge are on the one hand necessary and scientific, and on the other contingent and matters of opinion, so it is nevertheless that as sight is common in viewing all colors, whether permanent or changeable, so the art of knowing, that is to say, dialectic or logic, is one and the same doctrine in respect to perceiving all things. ${ }^{6}$

Tendo adotado o modelo de Rodolfo Agrícola através de seus estudos com Johannes Sturmius em Paris, Ramus não apenas reitera que a disciplina da dialética cuidará da invenção e da disposição, mas radicaliza a proposta, subtraindo essas partes da retórica e, também, subtraindo da gramática a parte da elocução.

Um dos aspectos fundamentais da lógica de Ramus é a centralização que dá aos loci - os tópicos, ou lugares. De acordo com Ong (2004, 105), as categorias na lógica de Ramus funcionam como lugares-comuns, fonte de argumentos para todos os tipos de matéria:

The items which will soon appear in Ramus' Dialectic as "arguments" and will be impaled on the bracketed tables of dichotomies have often been referred to as categories. But since they grow out of the topical tradition of Rudolph Agricola's Dialectical Invention, they are not really categories at all. As Ramus himself will make explicitly clear, they are simply these same topics or loci or "places". More explicitly, they are commonplaces, for they are sources of arguments common to all sorts of subjects and available to all as matters of common knowledge.

A proposição de uma lógica tópica, comum ao uso de todos para a invenção de argumentos para propósitos diversos, é central também na versão que Abraham Fraunce faz do modelo ramista em The Lawiers Logike. Segundo argumenta, os lugares da invenção são universais e adaptáveis para o uso de filósofos, juízes, advogados e, inclusive, homens comuns:

The Art of reasoning hath somewhat to doe in euerie thing, and nothyng is any thing without this one thing. Some Artes are applicable onely to some certyne subiect, but Logike is scientia scientiarum, as I said before, not tyed to one thing, but apt for anie thing, free from all, yet fit for all, framing orderly, prooving strongly, expounding plainly, perswading forcibly. [...] Men reason in schooles as Philosophers, in Wesminster as Lawyers, in Court as Lords, in Countrey as wordly husbands: whatsoeuer it bee, nay whatsoeuer thou canst imagine to bee, although it bee not, neuer was, nor neuer

${ }^{6}$ Petrus Ramus, Dialectique, apud Howell 1956, 154. 
shall bee, yet by reason it is inuented, taught, ordered, confirmed: as the description of fame in Virgil, of famine in Ouid, of Elysian fields, of Styx, of Acheron, of the golden apples, and a thousand such poeticall imaginations.

A lógica é, como diz Fraunce, "a arte da arte", ou "o instrumento dos instrumentos", pois a partir dela inventa-se tudo o que há e não há no mundo: tanto especulações morais quanto fantasias poéticas. Assim, para comprovar a força inventiva da lógica, Fraunce incita à leitura dos grandes poetas e oradores, onde se acha todo tipo de conceito: "Reade Homer, reade Demosthenes, reade Virgill, reade Cicero, reade Bartas, reade Torquato Tasso, reade that most worthie ornament of our English tongue, the Countesse of Pembrokes Arcadia". Como se viu acima, Fraunce exemplifica com poemas tanto a exposição dos tópicos em sua arte dialética quanto a exposição de tropos e figuras em sua arte retórica.

Conforme prenunciado por Ramus na ocasião da publicação de sua Lógica, Omer Talon, seu discípulo e colega em Paris, publicou, em 1544, as Institutiones Oratoriae. ${ }^{7}$ Nesse tratado, o autor define que cabem à retórica as partes da elocução e da antiga actio, ou seja, as partes que cuidam dos estilos e da projeção verbal e gestual. Na parte da elocução, definem-se os tropos e as figuras, com exemplos tirados de autoridades nos diferentes gêneros - Talon exemplifica na maioria das vezes com discursos de Cícero, mas também cita versos, sobretudo de Virgílio. Na parte da ação, discutem-se vícios e virtudes da pronúncia e da gestualidade do orador - voz e visão. Em 1557, Antoine Foclin (ou Foquelin, em outra grafia conhecida de seu sobrenome) publicou, em Paris, o tratado La Rhetorique Françoise d'Antoine Foclin, em que dá seguimento ao modelo ramista da retórica de Omer Talon, fazendo uma versão em vernáculo do que antes estava proposto em latim. Na dedicatória à princesa Mary Stuart - então residente da corte francesa e futura esposa do Dauphin -, Foclin escreve que sua arte retórica trará todo o conhecimento recolhido dos antigos, gregos e latinos, disposto conforme a nova proposição ramista de Omer Talon: "j'ay traduit les preceptes de Rhetorique, fidelement amassez des liures des anciens Rheteurs Grecz \& Latins, \& rengez en singulier ordre de disposition par Omer Talon, homme non moins excellent en cét art, que parfait en toutes autres disciplines". À maneira dos tratados de defesa da poesia compostos ao longo do século XVI, Foclin aplica a tópica de que a língua francesa é tão apta para a poesia quanto a grega e latina, desde que os autores observem a preceituação antiga no regramento de seus versos em vernáculo. Fazendo como Ronsard - em sua L'art poëtique -, Foclin incita à composição de tratados em língua 
francesa, com exemplificação de tropos e figuras feita a partir de versos de Pierre de Ronsard, Joachim Du Bellay, Ramis de Belleau e Jean-Antoine de Baïf, e de traduções francesas de Virgílio e outras autoridades antigas. A retórica de Abraham Fraunce é uma versão modificada da obra de Foclin - que, por sua vez, é uma versão "afrancesada" das Institutiones de Talon. ${ }^{8}$ Passemos, pois, a ela e a seus mais importantes elementos.

\section{A RETÓRICA ARCÁDIA DE FRAUNCE: PAIXÕES E AFETOS EM "VERSOS CONCEITUOSOS”}

Tendo em vista esses antecedentes, ${ }^{9}$ é adequado que se tome a arte retórica de Abraham Fraunce como uma versão em inglês de lições anteriores que já enfatizavam o domínio útil da retórica como preceituário e crítica (no sentido de deliberação de juízos) para a elocução. Fraunce introduz seu tratado definindo a retórica como uma arte da fala: "Rhetoricke is an Art of speaking", simplificando a expressão ars bene dicendi de Quintiliano e outros. ${ }^{10}$ Em seguida, aplicando o método de ramificações do modelo ramista, divide a retórica em duas partes, elocução e pronunciação: "Eloqution is the first part of Rhetorike, concerning the ordering and trimming of speech". Resumindo, a elocução trata da ornamentação do discurso, cuidando da escolha e da composição das palavras para a produção de efeitos nos variados estilos; e Fraunce passa então a uma distinção entre figuras (divindindo-as em figuras de palavra e de sentença) e tropos. Embora defina a retórica como uma arte da fala, Fraunce dá exemplos tirados quase sempre de poemas e não de discursos: em sua retórica "arcádia", não aparecem passos dos grandes oradores, dos diálogos filosóficos, de fábulas ou de prosa histórica. Tratando de figuras e de tropos, define-os com trechos selecionados de Homero, Virgílio, Tasso, Petrarca, Sidney, Spenser, Du Bartas, Garcilaso e

\footnotetext{
${ }^{8}$ A obra de Antoine Foclin, composta na década de 1550, é dedicada à jovem Mary Stuart, que então vivia na corte francesa. Quando a arte retórica de Fraunce foi publicada em Londres, já na década de 1580, Mary Stuart era prisioneira na corte protestante de sua prima, a rainha Elisabeth. Logo depois, seria condenada à morte por traição, em uma época em que a nobreza católica das ilhas britânicas sofria sérias perseguições. Talvez por um receio de associação a obras patrocinadas pela nobreza católica, não há, na arte retórica de Fraunce, menção alguma às artes retóricas de Talon e Foclin.

9 Há certamente diversos outros; para citar apenas os tratados ramistas publicados em inglês, havia o de Dudley Fanner, The Artes of Logike and Rhetorike, de 1584, e, antes, os discursos de Gabriel Harvey, Rhetor e Ciceronianus, publicados em 1577 mas que já circulavam na Universidade de Cambridge desde de 1569. cf. Howell 1956, 247-256.

${ }^{10}$ Cf. Foclin: "Rhetorique est vn art de bien \& eleganment parler"; e Omer Talon, seguindo Quintiliano: "Rhetorica, est doctrina bene dicendi".
} 
Boscán, principalmente, o que confere uma importante distinção a sua obra em meio às demais que tratam de retórica.

O segundo capítulo inicia a exposição dos tropos, que segue até o capítulo 11 - metonímia (dividida em: da causa, da coisa causada, do sujeito, do adjunto), ironia, metáfora e sinédoque (dividida em: da parte, do especial, do integral e do geral). Fraunce inclui também na lista de tropos, como Quintiliano na Institutio Oratoria, a alegoria e a hipérbole, embora não dê exemplos em versos; a menção a elas se dá em seguimento à própria definição de tropo:

A Trope or turning is when a word is turned from his naturall signification, to some other, so conueniently as that it seeme rather willinglie ledd than driuen by force to that other signification. This was first inuented of necessity for want of words, but afterwards continued and frequented by reason of the delight and pleasant grace thereof. Sometimes these Tropes bee excessiue, signifying in word, more than can bee true in deed, and then they are termed Hyperboles. The excellencie of tropes is then most apparant, when either manie be fitlie included in one word, or one so continued in manie, as that with what thing it begin, with the same it also end: and then it is called an Alegorie or Inuersion.

A metáfora recebe lugar destacado, como de hábito no costume prescritivo desde Aristóteles, mas é agora reconfigurada como elemento central: "There is no trope more flourishing than a Metaphore, especially if it be applied to the senses, \& among the senses chiefly to the eie, which is the quickest of all the senses." E Fraunce exemplifica o uso diversificado da metáfora que produz efeitos ora "majestosos" e "elevados", ora "lamentosos" e "dignos de pena". De Virgílio, seguem versos da Eneida, Geórgicas e Bucólicas: "Te duce, siqua manent sceleris vestigia nostri / Inrita perpetua soluent formidine terras" (Ecl. 4.13-14). Do soneto 23 de Philip Sidney: "Alas the race / Of all my thoughts, hath neither stop, nor start, / But onely Stella's eyes, and Stella's heart". Seguindo Quintiliano, Fraunce aponta o uso de amplificações hiperbólicas na construção metafórica, o que produz o efeito elevado e majestoso: "and by these hyperbollical metaphors the speech is made very loftie and full of majestie, when we attribute life and action, to dead and senseless things". Exemplifica, como Quintiliano, com Virgílio: "Pontem indignatus Araxes". ${ }^{11}$ E escolhe versos de Les Semaines, de Saluste du Bartas: "mais voy comme le mer / Me jette en mille mers, ou je crains d'abismer". E também de Boscán: "El sentir de mi sentido / tan profundo ha nauegado, / que me tiene

${ }^{11}$ Cf. Quintiliano 8.6.11 (ed. Russell 2001): Praecipueque ex his oritur mira sublimitas, quae audaci et proxime periculum translatione tolluntur, cum rebus sensu carentibus actum quendam et animos damus, qualis est <pontem indignatus Araxes>. 
ya engolfado / donde uiuo despedido / de salir à pied ni à nado". A longa e variada exposição de metáforas poéticas demonstra o papel central desse tropo como gerador de imagens que são conceituosas (conceipted, como Fraunce as nomeia) e ornamentadas retoricamente. Esse entendimento se fortalece com as reformulações propostas pelo modelo ramista. Como vimos acima, selecionam-se argumentos a partir das tópicas, que, então, são figurados retoricamente, promovendo uma fusão de lógica e retórica na produção dos conceitos metafóricos. Esse procedimento está na base da compreensão da imagem como "ornato dialético", conforme será preceituado por autores italianos e espanhóis, principalmente, no início do século XVII:

Com a redefinição dialética das tópicas, proposta principalmente por Ramus ou La Ramée e retomada por poetas e retores italianos e espanhóis, a metáfora passou a ser entendida como a matriz do engenho poético: "mãe do engenho", escreve Tesauro em Il cannocchiale aristotelico. Segundo a redefinição, a metáfora poética nasce diretamente das operações do engenho, que é uma faculdade natural simultaneamente dialética e retórica. Dialeticamente, o engenho descobre as semelhanças e as diferenças dos conceitos do tema, aplicando a ele as dez categorias aristotélicas. [...] As imagens resultantes são "ornato dialético", como então se conceitua, pois são imagens retóricas que figuram conceitos obtidos dialeticamente. ${ }^{12}$

Após os tropos, Fraunce segue tratando das figuras, a partir do capítulo 12. Define-as indicando sua distinção em relação aos tropos:

A figure is a certeine decking of speech, whereby the vsual and simple fashion thereof is altered and changed to that which is more elegante and conceipted. For as a Trope is of single wordes, so a Figure of coopled and conjoined: and as of wordes, some bee proper, some turned, so of speeches, some bee simple and natural, some finelie fashioned and figured artificiallie. A figure is either in the word, or in the sentence. A figure of the worde is that whereby the wordes doo sweetlie and fitlie sound among themselues. In these figures especially consisteth the conceipted pleasance and delicacie of speech.

O termo conceipted ("conceituoso") aparece com frequência em The Arcadian Rhetorike para referir um argumento inventivo ornamentado com tropos e figuras, artificioso e elegante, próprio do âmbito urbano e instruído das cortes..$^{13}$ Refere também o próprio argumento inventivo, quando ornamentado

\footnotetext{
${ }^{12}$ Hansen 2002, 58-9. Para examinar com mais amplitude a proposição teórica da imagem poética como "ornato dialético" na Inglaterra, seria necessário fazer uma análise conjunta das artes retóricas e dialéticas do período, como as de Fraunce, o que se pretende fazer numa etapa posterior desta pesquisa.

${ }^{13}$ O termo conceit, em inglês, é análogo ao concetto, concepto, concept usados com tanta frequência no vocabulário poético dos meios letrados italianos, espanhóis e franceses ao longo dos séculos XVI e XVII. É definido, no dicionário de John Florio, como "an apprehension of the minde" e muitas vezes refere o próprio argumento inventivo ou a agudeza. Cf. Florio 1598.
} 
com agudeza. Assim, o domínio da elocução não se dissocia da invenção dos argumentos mas a complementa, tornando os lugares inventivos "conceituosos". Ademais, não se dissocia tampouco do lugar social e político no qual o discurso da agudeza se forma e se conforma; as regras da arte da fala são promovidas no mesmo espaço em que depois serão reproduzidas, na poesia e nas demais artes. Logo após ter definido as figuras e dividido-as em figuras de palavra e de sentença, Fraunce interpõe três capítulos antes de retomá-las e expor exemplos. Os capítulos 13 e 14 tratam do que Fraunce chama de "Poeticall dimension": verso, ou metro, e rima, explicitando que em sua retórica arcádia os preceitos para poesia são centrais. Há uma longa exposição de metros, com nomenclatura a partir dos tipos de pés de que consistem: "Verse or meter is a poeticall dimension comprehending certaine feete setled in certaine places. A foote is a dimension of certaine syllables with a strict obseruation of distinct time or quantitie", e segue assim classificando os tipos de pés e os metros que compõem. Esse trecho da arte retórica de Fraunce evidencia as diversas tentativas de se praticar os hexâmetros dos versos antigos nas línguas vernáculas, como neste exemplo de Philip Sidney: "First shall a trustie Greyhound transforme himselfe to a Tyger" e neste do Conde d'Alsinois: "Voi de rechef, vn vers animé, vers digne de ton nom, / Vers, que la France reçoir, vers que la France lira". Além de figurar a nova poesia em vernáculo lado a lado com versos de Virgílio e outros antigos, firmando a autoridade de poetas contemporâneos cultos como Sidney e Spenser, Fraunce demonstra a versatilidade desses autores em variar o uso de pés diversos em um mesmo verso (alternando iambos e espondeus em um verso hexâmetro, por exemplo) e de compor em metros antigos pouco praticados como o anacreôntico. A exposição desses exemplos compõe uma Arcádia em que os novos poetas da corte dominam a arte antiga, emulando-a em todos os aspectos. Fraunce, ele mesmo poeta de versos hexâmetros, demonstra também a sua própria peritia ao expor esse tema.

O capítulo 15 consiste em uma breve pausa no trato da "dimensão poética" e adentra o campo da oratória: "Now followeth that of Orators, both vnlike that of Poets and alwaies vnlike itselfe. In prose auoid verse, vnlesse now and then a verse bee brought in out of some author, either for proofe or pleasure". Apesar disso, os exemplos ainda são de Philip Sidney, de trechos em prosa da Old Arcadia. A brevidade desse capítulo parece indicar que Fraunce realmente se abstém de comentar aspectos da elocução na oratória, privilegiando o que chama de "dimensão poética". A partir do capítulo 16, Fraunce volta a tratar de figuras, e dá início a uma longa lista de nomes e exemplos. Começa com as figuras de repetição de palavras e de sons idênticos ou semelhantes - epizêuxis, anadiplose, clímax, anáfora, epístrofe, símploce, epanalepse, epânodo, paronomásia e poliptoto. Os 
exemplos que apõe para cada figura são muito interessantes, pois consistem de uma seleção que frequentemente evidencia a emulação de versos de Homero e de Virgílio feita pelos poetas do século xvI, ou aquela feita entre os próprios poetas coetâneos. Pelo limite de espaço, é evidentemente impossível citar todos os exemplos aqui. No entanto, um caso específico merece ser exposto: trata-se de uma digressão iniciada no capítulo 25, quando Fraunce termina de elencar as figuras de repetição. Ele diz: "Before I leaue of to talk of these figures of words, I will here confusedlie insert a number of conceited verses, since all their grace \& delicacie proceedeth from the figures aforenamed." Essa inserção "confusa" de versos conceituosos (conceipted verses) exibe uma série de exemplos em que a técnica de repetição é levada ao extremo da agudeza, mostrando a versatilidade dos poetas. São casos exemplares que Fraunce expõe não apenas como registro de variedade técnica, mas também como receituário para futura emulação. Neste exemplo, ele começa com versos de Philip Sidney e em seguida arrola a mesma técnica praticada, antes, por Petrarca e Garcilaso:

Sir Philip Sidney hath a rime, wherein the last word of the first doth jumpe in sound with the middle word of the second, thus:

Vp, vp, Philisides, let sorrowes goe,

Who yeelds to woe, doth but increase his smart:

Doo not thy heart to plaintfull custome bring,

But let vs sing, \&c.

So Petrarch, fol. 153:

Mai non vo piu cantar com' io soleua,

$\mathrm{Ch}^{\prime}$ altrui non $\mathrm{m}^{\prime}$ intendeua, \&c.

And Garcilasso aegloga:

Filomena sospira en dolce canto,

En amoroso llanto se amanzilla

Gime la tortilla sobre el elmo, \&c.

Neste outro exemplo, Fraunce primeiro mostra um epigrama então atribuído ao imperador Adriano e, em seguida, diz que um conterrâneo o imitou com versatilidade, na descrição doce que fez na guerra de Troia:

Vt belli sonuere tuba, violenta peremit

Hippolyte Teuthranta, Lyce Clonon, Oebalon Alce,

Oebalon ense, Clonon iaculo, Teuthranta sagitta.

Oebalus ibat equo, curru Clonos, \& pede Teuthras.

[...] 
In imitation whereof, a countreyman of ours, in his sweete discription of the Trojan warre, hath made diuers: among the rest I remember these three:

Stemona sternit Ion, Ionem proturbat Acontes,

Mactat Aconta Pholus, Pholo Oebalus, Oebalum Astor,

Astora Thyodamas, \& Thyodamanta Lyceus. ${ }^{14}$

Fraunce cita diversos outros exemplos de "versos conceituosos" em que a agudeza reside na repetição de palavras e sons, como no caso dos serpentina carmina e dos versos que podem ser lidos de trás para frente. Para terminar, o autor arrola um exemplo de disseminação e recolha amplificada no Fairie Queene, de Spenser:

Wrath, iealousie, griefe, loue, doo thus expell:

Wrath is a fire, and iealousie a weede,

Grief is a flood, and loue a monster fell:

The fire of sparkes, the weede of little seede,

The flood of drops, the monster filth did breed:

But sparkes, seede, drops, and filth doo thus delay,

The sparkes soone quench, the springing seed outweede,

The drops drie vp, and filth wipe clean away,

So shall wrath, iealousie, griefe, loue, die and decay.

Em seguida, a partir do capítulo 26, Fraunce trata das "figuras de sentença", alegando que essas têm mais força de persuasão que as demais:

This shall suffice to haue spoken of figures in words: now follow the figures in Sentences, which in the whole sentence express some motion of the minde. These are more forcible \& apt to persuade, than those of words, which be rather pleasant and fit to delight. Generallie, as in tropes there is a certaine grace, in figures of words a kinde of delicacie, so in these of sentences, appeareth force and majestie.

Essa visão de sentença que "expressa um movimento da mente" e que, com o uso apropriado das figuras, tem força e é mais capaz de persuadir está muito próxima do entendimento de elocução presente nos tratados sobre a elocutio atribuídos a rétores gregos pós-aristotélicos, como Hermógenes. Em Peri Ideon, ou Tipos de Estilo, Hermógenes trata da elocução e dos elementos que a compõem: pensamento, figuras e composição, examinando como efetuam os variados estilos, que fazem surtir determinados

${ }^{14}$ Embora não dê a referência, esses versos do épico De Bello Troiano são de Joseph of Exeter, poeta inglês do século XII. Com frequência, Fraunce diz que cita de memória os versos que dá como exemplos em sua retórica arcádia, sem mencionar a obra ou o trecho da obra que está citando. Por esse motivo e também pela variação histórica nas versões de textos antigos que circulavam no século XVI, é difícil definir de onde Fraunce retira as passagens que copia. 
efeitos. ${ }^{15}$ Assim também Fraunce, que examina o verso poético como se tratasse de uma expressão feita de pensamento, figuras e composição (metro, nesse caso). A partir dessa definição de figura de sentença, Fraunce passa a arrolar exemplos de versos que expressam paixões e afetos como desespero, indignação, desdém, lamento e miséria, pena e comiseração. As figuras de sentença apontadas e comentadas são: exclamação e epifonema; epanortose; aposiopese; apóstrofe; prosopopeia; adubitação; comunicação; preocupação; permissão; concessão. Para cada uma delas, Fraunce dá exemplos sempre a partir de versos, comentando os efeitos gerados na dicção poética.

O segundo livro da retórica arcádia - bem menor em extensão do que o primeiro - trata da pronunciação, isto é, da antiga actio, que cuida dos preceitos de voz (altura, entonação, ênfase, duração das falas etc.) e de gestos (tanto o repertório simbólico das posições dos membros do corpo e de seu movimento quanto o efeito que tais movimentos produzem na dicção poética):

Of Eloquution which was the first part of Rhetorike, we haue spoken alreadie: now it remainth to talke of Vtterance or Pronunciation the second part. Vtterance is a fit deliuering of the speech alreadie beautified. It hath two parts, Voyce and Gesture, the one pertaining to the eare, the other belonging to the eye.

Pouco mencionando a oratória, Fraunce novamente se restringe a dar exemplos tirados de poemas, embora a preceituação para voz e gesto, inclusive em relação a adequação que se deve observar entre ambas, siga de perto o De Oratore ciceroniano. O pressuposto aqui é o entendimento corrente no âmbito letrado das cortes de que, pela prosopopeia, os poemas falam e encenam as coisas.$^{16}$ É relevante notar que Fraunce, ao tratar dos argumentos ou dos lugares discursivos "falados" ou "encenados" pelos personagens poéticos, não faz distinções entre silogismos ou entimemas e não avalia técnicas de amplificação. O que importa nessa segunda parte de sua retórica é o preceituário para a produção de efeitos de voz e gesto, lidando novamente com a ornamentação do discurso poético. Por esse motivo, todo o segundo livro na verdade se torna um exame da figura retórica da evidentia - sem que ela seja, porém, nomeada. A ação narrada deve ser posta "diante dos olhos" do espectador - regra mestra aristotélica da oratória. Mas, no caso da

\footnotetext{
${ }^{15}$ Quanto à circulação dos tratados helenísticos sobre o estilo no século XVI e a aplicação de seus preceitos na poesia da época, ver o importante estudo de Patterson 1970, Hermogenes and the Renaissance - Seven Ideas of Style.

${ }^{16}$ Cf., por exemplo, a definição dada por Florio: "a faining of any person to speake, a representing of persons".
} 
poesia, a ação dos personagens - que, pela figura da prosopopeia adquirem vida e capacidade de falar como se existissem - deve explicitar os movimentos do páthos, a indignação diante dos reveses da fortuna, o lamento da voz do amante, a gestualidade majestosa dos heróis etc. Assim, Fraunce preceitua para a evidentia da expressão facial de um personagem:

the chiefest force of the head is in the countenance, and of the countenance, in the eyes, which express liuelie euen anie conceit or passion of the mind: as therefore the face \& countenance must bee comelilie and orderlilie composed, so the eyes verie diligentlie are to be regarded. ${ }^{17}$

A dicção poética deve expressar vividamente (liuelie) as paixões da mente. E exemplifica com Tasso:

Leuò al fin gli occhi e disse, ò dio, che scerni

L'opre più occulte.

\section{Com Du Bartas:}

Etant donc de ce point saintement resolue,

Vers le pole elle eleue \& ses mains \& sa veue:

Et puis à basse vois prie ainsi l'Eternel.

O bon dieu \&c.

\section{E também com Boscán:}

Boluiendo al cielo sus cansados oios,

A los mayores dioses y menores, \&c.

Fraunce faz o mesmo quando preceitua certa inclinação da cabeça para denotar humildade, ou, ao contrário, prescreve a rigidez do braço direito levantado em posição horizontal para representar a força de palavras de comando. Em vários trechos, Fraunce diz que a escolha e a disposição das palavras devem também acompanhar o tipo de fala dos personagens, conforme a paixão que vai ser veiculada pela voz, segundo o decoro do estilo: "In pitie and lamentation, the voice must be full, sobbing, flexible, interrupted". Seguem exemplos, dentre eles este, de Boscán, que mimetiza o soluço da amante com a repetição de dulce:

${ }^{17}$ Cf. Cicero, De Oratore 3.59: "For by action the body talks, so it is all the more necessary to make it agree with the thought: and nature has given us eyes, as she has given the horse and the lion their mane and tail and ears, to indicate the feelings of the mind, so that in the matter of delivery which we are now considering the face is next in importance to the voice; and the eyes are the dominant feature in the face." 
Mi dulce bien, mi dulce esposo, y dulce

Coraçon mio, por quien todo me es dulce,

Pudiste tu mi bien tan gran trabaio,

Y peligro passar como has passado?

De outro lado, a voz indignada deve ser amarga, irritada, colérica e furiosa ("bitter, angrie, cholerike, and furious") - como a voz de Agamemnon (Hom. Il. 1.106-8):

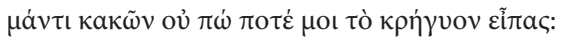

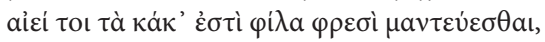

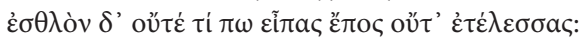

E a voz irada deve ser aguda, cortante, veloz e curta ("anger, shrill, sharpe, quicke, short") - como a de Netuno (Verg. A. 1.131-41):

Eurum ad se Zephyrumque vocat, dehinc talia fatur:

“Tantane vos generis tenuit fiducia vestri?

Iam caelum terramque meo sine numine, venti,

miscere, et tantas audetis tollere moles?

Quos ego-sed motos praestat componere fluctus.

Post mihi non simili poena commissa luetis.

Maturate fugam, regique haec dicite vestro:

non illi imperium pelagi saevumque tridentem,

sed mihi sorte datum. Tenet ille immania saxa,

vestras, Eure, domos; illa se iactet in aula

Aeolus, et clauso ventorum carcere regnet."

Na angústia e na dor de espírito, sem compaixão, a voz deve ser oca e vinda do fundo da garganta, gemente, como nestes versos de Torquato Tasso, no Re Torrismondo:

Ma che mi può giovar, s'io non m'ascondo

a me medesmo? Oimè, son io, son io, quel che fuggito or sono e quel che fuggo:

di me stesso ho vergogna e scorno ed onta,

odioso a me fatto e grave pondo.

Che giova ch'io non oda e non paventi

i detti e 'l mormorar del folle volgo,

o l'accuse de' saggi, o i fieri morsi

di troppo acuto o velenoso dente,

se la mia propria conscienza immonda

altamente nel cor rimbomba e mugge,

s'ella a vespro mi sgrida ed a le squille,

se mi sveglia le notti e rompe il sonno

e mille miei confusi e tristi sogni? 


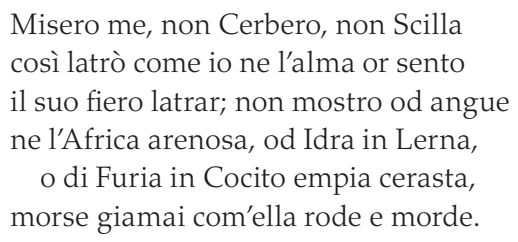

Em momentos de desejo, alívio, lisonja, complacência ou satisfação, a voz deve ser doce e submissa. ${ }^{18}$ Assim também no caso dos gestos, ou da expressão corporal descrita, com vividez, na dicção poética: devem ter variedade e acompanhar as paixões, seguindo o decoro do estilo. A cabeça e os olhos baixos expressam modéstia; o balançar da cabeça mostra lamento ou indignação; bater o pé é decoroso na dicção veemente, etc. Embora Fraunce, portanto, comente aspectos da actio que contribuam para a variedade da expressão e para o decoro das partes em relação ao todo da composição, os exemplos são tirados de poemas ou de (poucos) trechos em prosa da Old Arcadia de Sidney. Desse modo, a retórica arcádia de Fraunce nunca deixa de ser preceituário para a prática poética. Novamente, Fraunce faz uma adaptação dos preceitos para a oratória levando-os ao campo da poesia de seu tempo.

\section{RETÓRICA E POESIA: “A VARIETIE OF PASSIONS"}

Considerando o conjunto de preceitos e juízos expostos em The Arcadian Rhetorike, percebe-se que é conveniente, para o autor, tomar a elocutio como centro da retórica. A vasta possibilidade de comentar a ornamentação da dicção poética e os variados efeitos que produz, de forma concentrada e sem interferência de outras matérias, faz com que a obra de Fraunce realize diversas operações no âmbito da prática letrada inglesa de sua época, particularmente em relação à produção poética. A ordenação de sua obra, que prevê uma longa série de exemplos de poemas antigos e modernos para o comentário de cada ornamento retórico, produz analogias entre as obras, de várias formas. A presença de versos contemporâneos compostos em vernáculo ao lado de autoridades antigas promove a legitimação dos "novos

\footnotetext{
${ }_{18}$ Aqui, Fraunce segue a preceituação ciceroniana para a actio, adaptando a preceituação da oratória para a poesia. cf. Cicero, De Oratore 3.57-8 (ed. Rackham 2004): "For nature has assigned to every emotion a particular look and tone of voice and bearing of its own; and the whole of a person's frame and every look on his face and utterance of his voice are like the strings of a harp and sound according as they are struck by each successive emotion. [...] For one kind of tone must be taken by anger - shrill, hasty, with short abrupt clauses [...]. Another tone is proper for compassion and for sorrow, wavering, full, halting, in a mournful key".
} 
autores" como continuadores da prática poética culta. Como seus coetâneos da Pléiade francesa, Sidney e Spenser passam a habitar o rol dos chamados poètes classiques - aqueles pertencentes ao elenco de autores constituído como normativo mas aberto a novos acréscimos de uma seleção contemporânea. Se a analogia entre os versos de antigos e modernos não se faz por gênero - já que, ao lado dos épicos de Homero, Virgílio e Tasso aparecem os versos bucólicos em estilo elegante de Spenser e Sidney, ou os versos amorosos dos sonetos de Boscán e Garcilaso -, o que une esse conjunto tipificador produzido por Fraunce são as operações de efetuação de estilos envolvendo ornamentos retóricos. Pelo decoro da circunstância - e não pela unidade de gênero - os versos arrolados exibem afetos concernentes a trechos específicos de cada obra: assim, Fraunce exemplifica o desespero conforme efetuado pela figura da exclamatio na fala de Tétis a Aquiles, no canto I da Ilíada; na fala de Armida a Godfrey, em Gerusalemme Liberata, de Torquato Tasso; na fala de Bagos quando vê Holofernes morto, em La Judit, de Saluste du Bartas; na voz lírica de um soneto de Boscán e em outros exemplos. O que reúne esses versos, portanto, a despeito da variedade de gênero em que foram compostos, é o decoro que torna adequada a efetuação de um determinado efeito ou afeto em partes menores que compõem o todo da obra poética. Nessas partes menores, o decoro age na observância do estilo da fala em relação ao personagem e à matéria, como preceitua Fraunce neste trecho: "we must diligentlie take heed that the person thus represented haue a speech fit and conuenient for his estate and nature" (livro I, cap. 31).

Além de seguir seus modelos mais imediatos de composição - as Institutiones Oratoriae, de Omer Talon, e La Rhetoriqve Françoise, de Antoine Foclin, como vimos anteriormente -, a obra de Abraham Fraunce faz circular também preceitos figurados em artes poéticas continentais, como a Arte Poetica de Antonio Minturno, publicada em 1559, em Nápoles. O título estendido da obra dá uma clara ideia do que se trata nela: L'Arte Poetica del signor Antonio Minturno, Nella quale si contengono i precetti Eroici, Tragici, Comici, Satirici, e d'ogni altra Poesia: Con la dottrina de' Sonetti, Canzoni, ed ogni sorte di Rime Toscane, dove s'insegna il modo, che tenne il Petrarca nelle sue opere. Como se vê, Minturno, diferentemente de Fraunce, elege tratar dos gêneros poéticos e das formas de composição de poesia em vernáculo, exemplificando com versos de Petrarca. Porém, há em toda a obra de Minturno a produção de analogias entre as formas poéticas antigas e as vernaculares que as emulam, com foco na elocução e na produção dos afetos, como mostram os títulos dos dois capítulos que encerram o Primeiro Livro de sua arte poética: "Delle Passioni, ed Affetti, Amore, Odio, Ira, Mansuetudine, Paura, Confidenzia, Misericordia, Sdegno, Invidia, Gelosia, Emulazione, Dispregio, Vergogna, Sfacciataggine", e "De' Luoghi, onde le passioni deri- 
vano, con gli esempli". Tais exemplos são tirados quase sempre de sonetos, odes e canções de Petrarca, mas com frequência são relacionados a versos de Virgílio e outros poetas antigos. Assim, como ocorre na retórica arcádia de Fraunce, também em Minturno o leitor se depara com uma vasta quantidade de versos que exemplificam a produção das paixões e dos afetos. Mais ainda, esses versos aparecem desprendidos do conjunto da obra a que pertencem, fazendo com que o decoro se aplique à parte do poema sob análise, em que determinada paixão ou afeto se realiza. Desse modo, a obra de Minturno se dá também como preceituação retórico-poética dos afetos.

Se comparada a outras artes retóricas ou mesmo a artes poéticas inglesas de seu tempo, a obra de Fraunce, pelo o que vimos até aqui, se diferencia radicalmente nestes aspectos: na eleição do modelo ramista, que atribui à retórica as partes da elocução e da pronunciação; na extensa exemplificação de tropos, figuras e afetos de voz e gesto com versos de autores antigos e contemporâneos, compostos em diferentes línguas; na eleição do decoro como princípio regente da composição das paixões e dos afetos expressos nas falas poéticas; no grau de detalhamento desses múltiplos afetos no exame da produção de estilos; na ausência de referência aos três genera dicendi da oratória latina. Como temos visto, tais aspectos não são aleatórios ou desprendidos uns dos outros; ao contrário, parecem apontar para um entendimento específico de elocução poética que valoriza sobremaneira a produção dos afetos e que, por conseguinte, reformula a preceituação antiga para a unidade de estilo nos gêneros poéticos. É muito claro ver como as artes retóricas inglesas que antecedem a de Fraunce reforçam a preceitução para a oratória: seguem a divisão da retórica em deliberativa, judicial e demonstrativa, comentando casos exemplares; elegem a persuasão como finalidade da arte retórica; formulam os três genera dicendi conforme Cícero e a Rhetorica ad Herennium; exemplificam figuras e tropos quase sempre com passos de oradores, como faz Quintiliano, etc. ${ }^{19}$ Assim se dá em The Arte of Rhetorike (1553), de Thomas Wilson, a primeira grande obra do gênero a ser publicada em inglês. Mesmo as obras que se concentram na exposição e comentário da elocução, como $A$ Treatise of Schemes and Tropes (1550), de Richard Sherry, arrolam definições tiradas principalmente de Cícero e Quintiliano, sem muitos exemplos. No caso de The Garden of Eloquence (1577), de Henry Peacham, embora as definições também sigam as de preceptivas latinas, os exemplos são dados quase sempre a partir de trechos bíblicos, favorecendo a oratória sacra. Nas artes poéticas coetâneas, como The Arte of English Poesie (publicada apenas em 1589, embora uma versão abreviada já circulasse desde a década de 1560), de

${ }^{19}$ É certo também que, pela função que pretendem exercer, tais artes retóricas procedem a uma sistematização bastante simplificada das doutrinas formuladas por Cícero, Quintiliano e outros. 
George Puttenham, percebe-se igualmente a predominância da preceituação latina, então adaptada para a composição poética. Quando define tropos e figuras, refere-se com frequência a Quintiliano; quando trata da eloquência, cita Cícero. Ao tratar do estilo em poesia, Puttenham adverte que não se deve considerar trechos ou partes de uma obra, mas toda a extensão dela:

Style is a constant and continual phrase or tenor of speaking and writing, extending to the whole tale or process of the poem or history, and not properly to any piece or member of a tale..$^{20}$

E aplica os três genera dicendi para orientar a produção de estilo, tendo em vista a matéria central da obra poética:

For they be matter stately and high, and require a style to be lift up and advanced by choice of words, phrases, sentences, and figures, high, lofty, eloquent, and magnific in proportion. So be the mean matters to be carried with all words and speeches of smoothness and pleasant moderation; and finally the base things to be holden within their tether by a low, mild, and simple manner of utterance, creeping rather than climbing, and marching rather than mounting upwards with the wings of the stately subjects and style.

Nota-se que a dicção de Puttenham é vívida e variada, no estilo da prosa ciceroniana aclamada a seu tempo. Reside aí um visível contraste em relação à prosa enxuta de Fraunce, presente em toda a sua retórica arcádia; essa distinção evidencia os modelos de imitação e de preceituação de um e outro autor.

Seguindo modelos continentais que desde a primeira década do século advogavam a composição de poesia nos vernáculos, Puttenham produz uma extensa compilação de argumentos em favor da poesia, em geral, e da poesia inglesa, em particular, formando uma narrativa de origem e grandeza da língua e de seus poetas. ${ }^{21}$ Desde Chaucer e Lydgate, segundo Puttenham, a poesia composta em inglês seguiria tendência crescente de refinamento e observância dos preceitos antigos, tornando-se já perfeita na segunda metade do século xvi, na prática de Sidney, Spenser e outros. Assim como Fraunce, Puttenham também realiza a tarefa de autorizar a prática poética de seu tempo, alçando-a à altura da poesia antiga e dando diversos exemplos de poemas coetâneos no uso de figuras e tropos, expondo casos de agudeza e versatilidade, etc. Mas Puttenham não segue de forma

${ }^{20}$ Book 1, Chapter 5. Um pouco adiante, no mesmo capítulo, Puttenham afirma saber que há coetâneos seus que julgam ser possível fazer interferência de estilo elevado, por exemplo, em matéria humilde; mas diz aceitar esse procedimento apenas com sérias restrições.

${ }^{21}$ Esse mesmo mecanismo pode ser visto em diversas artes poéticas, como a Art Poetique (1548) de Jacques Peletier, La defence et illustration de la langue françoys (1549) de Joachim du Bellay, De Poeta (1555), de Minturno e outras. A respeito, ver Vickers 2003, em especial a partir da p.191. 
sistêmica um método tipificador; ao contrário de Fraunce, não mostra claramente como a poesia culta vernacular é análoga à poesia antiga, dado que a emula não apenas nos argumentos como nos próprios mecanismos retóricos da composição poética. Nesse sentido, a retórica arcádia de Fraunce é mais eficaz, pois, como vimos nos diversos exemplos dados acima, ela oferece uma sequência ininterrupta de casos em que a poesia vernacular imita a antiga, colocando-os diante dos olhos do leitor, expondo as adaptações necessárias que são feitas em cada língua e as possibilidades de se realizar a emulação com grande versatilidade. Nas exposições de versos conceituosos, o engenho do artífice e a agudeza da dicção poética são colocados sistematicamente em evidência, formando um novo conjunto de modelos a serem imitados pelos poetas da época. Essa operação revela a natureza prescritiva da arte retórica de Fraunce, que não apenas descreve os procedimentos retórico-poéticos mas preceitua seu uso na produção letrada de seu tempo, regulando a noção de decoro da composição. ${ }^{22}$

Em seu livro seminal sobre a prática poética dos séculos Xvi e xviı na Inglaterra, Elisabethan and Metaphysical Imagery, Tuve (1965) argumenta que a adoção do modelo ramista para a arte retórica não resulta em uma redução desta a manuais de estilo ou a uma mera ornamentação dos discursos. Se à lógica caberá a invenção dos lugares de argumentação propositiva e silogística para uso em todos os âmbitos dos discursos - tanto aqueles que tratam de postulados científicos, teológicos ou filosóficos quanto os que tratam dos argumentos opinativos e imaginativos -, torna-se pois legítimo que o poeta seja dialético quando sustenta a invenção poética em silogismos e entimemas. Tomando como exemplo o que se convencionou chamar de "a poesia metafísica inglesa", a amplificação da função lógica da imagem evidencia como a noção de decoro havia sido radicalizada, fazendo valer para a poesia lírico-amorosa proposições dialéticas ampliadas como antes se usava apenas no gênero elevado. Como vimos, a retórica arcádia de Fraunce não trabalha com os três genera dicendi da tradição latina quando preceitua a efetuação de estilos pela figuração das paixões e dos afetos; em vez disso, considera cada conceito poético que examina como uma unidade de estilo, impondo a ele um decoro de circunstância. Tal prática coloca em evidência a possibilidade de se efetuarem diversos estilos em uma mesma obra poética, realizando assim uma flexibilização da relação de decoro a gênero. Quando se considera a poesia inglesa composta a partir da década de 1590, como as produções poéticas de John Donne em gêneros diversos e a produção dramática con-

${ }^{22}$ Nesse sentido, fica evidente o anacronismo da aplicação do termo "crítica literária" às artes retórico-poéticas desse tempo, já que o caráter descritivo delas está completamente a serviço de sua função prescritiva. 
temporânea de Shakespeare e Marlowe, por exemplo, nota-se que as interferências de estilos variados dentro de um mesmo gênero se tornam uma prática sistemática e cada vez mais comum. Quando se considera, ainda, a poesia coetânea de Góngora, Quevedo, Lope de Vega, Tasso, Marino e tantos outros "poetas da agudeza", percebe-se que a mistura de estilos forçava uma nova legibilidade do decoro poético; isto é, uma forma flexibilizada de aplicação do decoro aos gêneros. Pelo que vimos, a retórica arcádia de Abraham Fraunce integra esse âmbito de reformulações de normas antigas e de novas perspectivas dadas à prática letrada, colocando a poesia - ou a "dimensão poética", como diz - no centro de sua preceituação retórica.

\section{REFERÊNCIAS}

Buxton, John. 1966. Sir Philip Sidney and the English Renaissance. London: Macmillan. Florio, John. 1598. A Worlde of Wordes, Or Most copious, and exact Dictionarie in Italian and English [...]. London.

Foclin, Antoine. 1555. La Rhetorique Francoise D'Antoine Foclin de Chauny en Vermandois, A Tresillustre Princesse Madame Marie Royne D'Ecosse. Paris: André Wechel.

Fraunce, Abraham. 1588. The Arcadian Rhetoric: Or The Praecepts of Rhetoric made plaine by examples, Greeke, Latin, English, Italian, French, Spanish [...]. London: Thomas Orwin.

Fraunce, Abraham. 1588. The Lawiers Logike, exemplifying the praecepts of Logike by the practice of the common Lawe. London: William How.

Grigera, L. L. 1994. La Retórica en la España del Siglo de Oro. Salamanca: Ediciones Universidad Salamanca.

Hansen, J. A. 2002. "Fênix Renascida \& Postilhão de Apolo: uma introdução." In Poesia seiscentista, org. Alcir Pécora. São Paulo: Hedra.

Hansen, J. A. 2000. "Retórica da agudeza." Letras Clássicas 4:317-342.

Harvey, Gabriel. 1580. A Gallant familiar Letter, containing an Answer to that of M. Immerito, with sundry proper examples, and some Precepts of our English reformed Versifying. In Three Proper Letters, lately passed between two university men [...]. London: Henrie Bynneman.

Howell, W. S. 1956. Logic and Rhetoric in England, 1500-1700. Princeton: Princeton University Press.

Innes, D. C., ed. 1999. Demetrius: On Style. Cambridge, MA: Cambridge University Press.

May, S. W. 2011. "Marlowe, Spenser, Sidney and - Abraham Fraunce?" Review of English Studies, 62:30-63.

Oliver, H. J. 1968. Marlowe: The Revels Plays: Dido Queen of Carthage and The Massacre at Paris. London: Methuen \& Co Ltd.

Ong, W. J. 2004. Ramus - Method, and the Decay of Dialogue. From the art of Discourse to the Art of Reason. Chicago: The University of Chicago Press. 
Patterson, A. M. 1970. Hermogenes and the Renaissance - Seven Ideas of Style. Princeton: Princeton University Press.

Rackham, Harris, ed. 2004. Cicero: De Oratore. Cambridge-London: Harvard University Press.

Russell, Donald, ed. 2001. Quintilian: The Orator's Education. London: Cambridge University Press.

Silvares, Lavinia. 2009. "A poesia inglesa e a retórica aristotélica: a atualidade dos discursos poéticos e preceptivos no século XVI." Viso: Cadernos de Estética Aplicada 6: 1-20.

Tuve, Rosemund. 1965. Elizabethan and Metaphysical Imagery: Renaissance Poetic and Twentieth-Century Critics. Chicago: The University of Chicago Press.

Vickers, Brian. 2003. English Renaissance Literary Criticism. Oxford: Clarendon Press.

Wooten, C. W., ed. 1987. Hermogenes: On Types of Style. Chapel Hill: The University of North Carolina Press.

Abstract. Among the arts of rhetoric composed in England in the second half of the 16th century, Abraham Fraunce's The Arcadian Rhetorike (1588) presents a remarkable structural distinction. If, on the one hand, the rhetorical treatises of the period usually gave the ancient 5-part division of rhetoric, on the other hand Fraunce's work gave a 2-part division of rhetoric: Elocution and Pronunciation. Closely following the model proposed by Petrus Ramus, Fraunce introduces in England the attribution of inventio and dispositio to Dialectics only, and elocutio and actio to Rhetoric only. Giving examples of tropes, figures, voice and gesture extracted from poems in Greek, Latin, English, Italian, French, and Spanish - from Homer, Virgil, Sidney, Spenser, Petrarch, Tasso, Du Bartas, Boscán and Garcilaso -, Fraunce shows the rhetorical mechanisms of poetry. In this paper, I intend to argue that the choice of the Ramist method allows Fraunce to construct an "Arcadian" rhetoric, focusing on what he calls a "poeticall dimension". In order to do this, I propose to (1) present the main characteristics of Fraunce's art of rhetoric, analyzing the historical circumstances of its composition; (2) examine the relationship that it maintains with other rhetorical and poetical treatises; and (3) discuss the importance it had to the writing of poetry in the later half of 16th century England. Keywords. Rhetoric, Poetry, 16th century, The Arcadian Rhetorike, Abraham Fraunce. 